\title{
PROFIL PEMAHAMAN NATURE OF SCIENCE (NOS) DI SEKOLAH DASAR
}

\author{
Muh.Erwinto Imran'1) \\ 1) Universitas Muhammadiyah Makassar \\ Ari Widodo2) \\ 2) Universitas Pendidikan Indonesia
}

\begin{abstract}
Abstrak
Penelitian ini bertujuan untuk menganalisis pemahaman siswa dan guru terhadap aspek Nature of Science (NOS) di sekolah dasar di Kabupaten Enrekang Sulawesi Selatan dan Kabupaten Purwakarta di Provinsi Jawa Barat yang terdiri dari Basis Empiris (Empiris Base), Tentatif (Tentative), Teori dan Hukum (Theories and Law), Keterlibatan Sosial Budaya (Socio Cultural embeddednes), Kreativitas (Creativity), Metode Ilmiah (Scientific Method), dan Subjektif (Subjective). Hasil penelitian diharapkan dapat menjadi masukan bagi Guru Sekolah Dasar dalam meningkatkan pemahaman dan kualitas siswa di sekolah dasar. Penelitian ini dilakukan dengan menggunakan metode elaborative yang melibatkan 45 siswa dan 2 guru kelas $\mathrm{V}$ sekolah dasar. Hasil penelitian menunjukkan bahwa pada umumnya responden pada penelitian ini menganggap bahwa aspek-aspek Nature of Science (NOS) harus dilakukan dan dipahami. Secara umum responden pada penelitian ini merasa setuju dengan indikator-indikator Nature of Science (NOS, namun ada beberapa aspek yang dianggap tidak setuju. Hasil penelitian ini berimplikasi terhadap peninjauan pembelajaran sains dan aspek-aspek pendukungnya.
\end{abstract}

Kata Kunci $\quad$ : Nature of Science (NOS), IPA, Sekolah Dasar 


\section{PENDAHULUAN}

Pendidikan

bertujuan

untuk

mempersiapkan manusia yang memiliki kemampuan hidup sebagai pribadi produktif, kreatif, inovatif, dan afektif serta mampu berkontribusi pada kehidupan bermasyarakat, berbangsa, dan bernegara. Buchori (2001) bahwa pendidikan yang baik adalah pendidikan yang tidak hanya mempersiapkan para siswanya untuk sesuatu profesi atau jabatan, tetapi untuk menyelesaikan masalah-masalah yang dihadapinya dalam kehidupan sehari-hari. Dalam pelaksanaan pembelajaran untuk mengetahui keberhasilan siswa, guru perlu mengadakan penilaian, termasuk penilaian terhadap pemahaman pada materi yang telah dipelajari. Untuk mengetahui seberapa jauh pemahaman siswa dapat dilihat dari kemampuan siswa dalam menjelaskan atau mendeskripsikan suatu objek pembelajaran IPA dan dapat menyelesaikan masalah-masalah terkait materi yang dipelajari. Penyelesaian masalah-masalah berkaitan erat dengan kemampuan nature of science (NOS) siswa. Kemampuan NOS yang berbeda akan mempengaruhi hasil penyelesaian masalahmasalah.

Aspek-aspek nature of science (NOS) yang paling banyak dijumpai dalam pendapat para ahli terkait NOS, yaitu Basis
Empiris (Empiris Base), Tentatif (Tentative), Teori dan Hukum (Theories and Law), Keterlibatan Sosial Budaya (Socio Cultural embeddednes), Kreativitas (Creativity), Metode Ilmiah (Scientific Method), dan Subjektif (Subjective)). Pemahaman NOS diyakini sebagai titian emas perkembangan dan pengembangan sikap, keterampilan, dan pengetahuan peserta didik. Pemahaman Nature of Science (NOS) membantu siswa untuk mengembangkan kekuatan penalaran, berpikir dan penerapan pengetahuan ilmiah serta juga membantu dalam mengembangkan sikap positif di antara siswa

Siswa memerlukan bekal kemampuan untuk survive dan sukses dalam menjalani hidup di masyarakat yang penuh dengan tantangan, bukan hanya membekali dengan aspek materi saja karena kehidupan saat ini lebih dinamis oleh perkembangan Ilmu Pengetahuan dan Teknologi (IPTEK). Siswa dapat mengatasi tantangan tersebut apabila memiliki pemahaman nature of science (NOS). (Akerson et al. 2000) menyarankan bahwa pendekatan eksplisitreflektif terhadap instruksi NOS yang disematkan didalam konten pembelajaran sains tidak hanya akan memudahkan pengembangan sains pandangan NOS guru, tapi mungkin akan membantu guru menerjemahkannya pemahaman tentang 
praktik aktual dalam kelas. Siswa mampu menggunakan pemahaman nature of science (NOS) untuk menganalisis sesuatu yang berguna atau tidak berguna bagi dirinya, keluarga, masyarakat dan bangsanya di masa depan. Instrumen dikembangkan berdasarkan asumsi bahwa siswa memandang dan menafsirkan pernyataan dengan cara yang sama seperti yang dilakukan peneliti. Namun, penelitian telah menunjukkan bahwa siswa dan peneliti menggunakan bahasa secara berbeda dan ketidakcocokan ini hampir pasti menyebabkan salah tafsir terhadap pandangan siswa tentang NOS di masa lalu (Lederman \& O'Malley, 1990).

Beberapa penelitian tentang hasil belajar selama beberapa dekade terakhir secara konsisten menunjukkan bahwa siswa dan pengajar gagal memahami NOS (Lederman 1992, 2007). Hal ini disebabkan masalah dalam pemahaman siswa tentang NOS tidak terlepas dari pemahaman NOS guru mereka (Lederman 1992)

Baru-baru ini, dua alat penilaian NOS multi-dimensi dikembangkan oleh Tsai dan Liu (2005), dan Chen (2006), masingmasing. Instrumen Tsai dan Liu, menggunakan skala Likert 5 poin, dirancang untuk menilai pandangan epistemologis siswa tentang sains (SEVs). Perkembangan SEVs didasarkan pada literatur dan data wawancara yang ada yang dikumpulkan oleh para peneliti. Saat ini, alat penilaian NOS yang paling berpengaruh pada pandangan NOS mungkin adalah kuesioner.

Berdasarkan latar belakang diatas, menarik peneliti untuk mencoba mengungkap pemahaman NOS Siswa dan Guru Sekolah Dasar Ditinjau dari pengetahuan dan latar belakang yang dimiliki. Dengan mengetahui hal tersebut diharapkan dapat mengetahui bagaimana pemahaman mereka tentang nature of science (NOS) melalui instrument yang telah dikembangkan, sehingga selanjutnya guru mampu membuat rancangan pembelajaran agar didapat pemahaman siswa yang sesuai dengan tujuan pembelajaran yang pada gilirannya akan meningkatkan prestasi siswa.

Pengembangan instrument dilakukan untuk memodifikasi dan mengembangkan instrumen yang bertujuan untuk meningkatkan validitas dan meminimalkan kemungkinan salah interpretasi persepsi responden. Setiap aspek NOS ini sendiri tidak mewakili sifatnya sains, dan sulit untuk menggambarkan aspek NOS yang spesifik sebagai perbedaan satu sama lain, Sebaliknya, mereka saling berhubungan (Osborne et al 2003). Tampak bahwa kuesioner terbuka disertai wawancara akan menghasilkan hasil penilaian yang valid 
dan bermakna. Namun, alat ini mungkin tidak sesuai dengan alat standar dalam penilaian skala besar. Di sisi lain, penelitian sebelumnya menyarankan bahwa alat penilaian yang diturunkan secara empiris secara signifikan akan mengurangi ambiguitas yang disebabkan oleh masalah bahasa. Oleh karena itu peneliti telah mengembangkan instrumen NOS, dengan menggabungkan pendekatan kuantitatif dan kualitatif untuk menilai pandangan siswa tentang bagaimana pengetahuan hakikat sains.

\section{METODE}

Penelitian ini bertujuan untuk menemukan informasi tentang pemahaman Nature of Science (NOS) pada siswa sekolah dasar. Penelitian ini dilakukan dengan menggunakan pemberian angket melibatkan 45 siswa dan 2 guru kelas dengan metode elaboratif dengan Pengumpulan data dalam penelitian ini menggunakan instrument angket dengan pertanyaan disusun oleh peneliti berdasarkan aspek-aspek Nature of Science (NOS) yang harus dimiliki siswa dan guru yang terdiri dari Basis Empiris (Empiris Base), Tentatif (Tentative), Teori dan Hukum (Theories and Law), Keterlibatan Sosial Budaya (Socio Cultural embeddednes), Kreativitas (Creativity), Metode Ilmiah (Scientific Method), dan
Subjektif (Subjective). Selanjutnya data hasil penelitian di lapangan dianalisis secara statistik deskriptif .

Data hasil penelitian ini disusun berdasarkan data yang diperoleh dari kegiatan penelitian pemahaman nature of science (NOS) yang telah dilaksanakan di SD Islam Terpadu Cendekia Purwakarta Kabupaten Purwakarta Provinsi Jawa Barat dan SD Negeri Kecil Leon Kecamatan Enrekang Kabupaten Enrekang Provinsi Sulawesi Selatan yang dilaksanakan pada bulan November 2017. Subjek penelitian siswa kelas 5 sebanyak 45 siswa (30 siswa di SD Islam Terpadu Cendekia Purwakarta dan 15 di SD Negeri Kecil Leon Kecamatan Enrekang). Selama penelitian berlangsung dilakukan pengamatan terhadap aktivitas siswa dan pemahaman nature of science (NOS) siswa. Pada pertemuan peneliti melakukan penilaian terhadap pemahaman Nature of Science (NOS) dengan menggunakan instrument angket.

\section{A. Guru}

Pembelajaran Ilmu Pengetahuan Alam di kelas rendah harus menekankan pada pemberian pembelajaran secara mendalam agar mereka mampu menguasai sejumlah keterampilan dalam setiap kegiatan belajar mengajar. Tujuan pembelajaran tersebut dapat tercapai dengan baik jika guru dalam mengajarkan menggunakan metode yang dapat membuat 
siswa lebih semangat dan mudah dimengerti. Penelitian Pemahaman nature of science (NOS) tersebut pada penelitian 2 sekolah di Kab. Purwakarta dan Kabupaten Enrekang ini masing-masing dilakukan oleh guru yang mengajar di setiap kelas 5 di sekolah tersebut. Masing-masing guru yang mengajar dalam penelitian ini memiliki pengalaman mengajar yang cukup lama, Guru SD Purwakarta telah mengajar 4 tahun lebih dan guru lainnya telah mengajar 5 tahun. Kedua pengajar ini semuanya berjenis kelamin laki-laki SD Islam Terpadu Cendekia Purwakarta Kabupaten Purwakarta Provinsi Jawa Barat dan SD Negeri Kecil Leon Kecamatan Enrekang Kabupaten Enrekang Provinsi Sulawesi Selatan.

\section{B. Siswa}

Latar belakang siswa memiliki pengaruh terhadap pengetahuan, kemampuan dan keterampilan yang dimiliki siswa sehingga perlu seorang guru mengetahuI setiap latar belakang peserta didiknya untuk memudahkan dalam mengajar. Siswa disetiap sekolah lokasi penelitian memiliki rata-rata umur 11 tahun

\section{Sekolah}

Mutu pendidikan yang baik bukan hanya dibebankan kepada pemerintah pusat, melainkan sekolah sebagai pelaksana pendidikan harus membenahi manajemen, mutu dan SDM sehingga menghasilkan bibit unggul di dunia pendidikan. Dalam penelitian pemahaman nature of science (NOS) ini dilakukan pada lokasi Sekolah dasar. Rician data sekolah dapat dilihat pada table di bawah ini. Aspek-aspek nature of science (NOS) sebagai berikut:

\section{1) Tentative}

Pengetahuan ilmiah bukanlah sesuatu yang mutlak kebenarannya dan tanpa kesalahan. Pengetahuan ilmiah dapat berubah (disempurnakan) dengan bukti pengamatan baru dan dengan reinterpretasi pengamatan yang ada.

\section{2) Empiris Base.}

Didasarkan pada data/bukti yang didapat dari observasi dengan panca indera dan/atau percobaan.

\section{3) Theories and Law}

Pengetahuan ilmiah dapat berupa hukum atau berupa teori. Hukum menggambarkan hubungan, pengamatan atau persepsi, fenomena di alam. Hukum biasanya disertai dengan rumus matematis. Teori adalah penjelasan yang disimpulkan untuk fenomena alam dan mekanisme hubungan antara fenomena alam.

\section{4) Socio Cultural embeddednes}

lmu pengetahuan adalah hasil usaha manusia, oleh karena itu, proses mendapatkan pengetahuan ilmiah dipengaruhi oleh masyarakat dan budaya di mana ia dipraktekkan. Sistem Nilai dan 
budaya akan mempengaruhi apa dan bagaimana ilmu pengetahuan dilakukan, ditafsirkan, dan diterima.

\section{7) Creativity}

Pengetahuan ilmiah tercipta dari imajinasi manusia, kreativitas dan penalaran logis. Dengan kreativitas ini Pengetahuan ilmiah akan terus berkembang. Penciptaan Pengetahuan ilmiah ini didasarkan pada perencanaan, pengamatan dan kesimpulan yang kreatif.

\section{5) Scientific Method}

Tidak ada sebuah metode ilmiah yang pasti dan berlaku universal. Untuk melakukan penelitian, para ilmuwan bebas untuk menggunakan metode apapun asalkan dapat dipertanggung jawabkan Indikator:

\section{6) Subjective}

Subyektivitas pribadi tak dapat terhindarkan dalam ilmu pengetahuan. Beberapa aspek pribadi akan mempengaruhi. seperti nilai pribadi, kepercayaan, agenda diri, dan pengalaman sebelumnya akan mempengaruhi apa dan bagaimana seorang ilmuwan melakukan pekerjaannya

\section{HASIL DAN PEMBAHASAN}

Penelitian ini mengembankan instrument yang didesain untuk menjelaskan kualitas pemahaman nature of science (NOS) siswa dan guru di sekolah dasar. Pengembangan instrument ini didesain untuk membantu siswa memaknai setiap konsep pada nature of science (NOS) dalam menjelaskan fakta kehidupan seharihari. Untuk mencapai tujuan tersebut peneliti mengembangkan instrument yang ide utamanya mengajak siswa melakukan berdasarkan aspek-aspek nature of science (NOS) yang harus dimiliki siswa dan guru yang terdiri dari Basis Empiris (Empiris Base), Tentatif (Tentative), Teori dan Hukum (Theories and Law), Keterlibatan Sosial Budaya (Socio Cultural embeddednes), Kreativitas (Creativity), Metode Ilmiah (Scientific Method), dan Subjektif (Subjective). Siswa dikatakan telah mampu berpola pikir seperti ilmuwan atau peneliti ilmiah (scientist) agar bisa mengembangkan ilmu pengetahuan dan teknologi apabila mampu membudayakan proses penelitian/ilmiah, salah satunnya seperti yang dikemukakan Kothari (2004) bahwa pedoman prosedural mengenai proses penelitian/ilmiah adalah: (1) merumuskan masalah penelitian, (2) survei literatur yang luas, (3) mengembangkan hipotesis, (4) menyusun desain penelitian; (5) menentukan desain sampel, mengumpulkan data, (7) pelaksanaan proyek, (8) analisis data, (9) pengujian hipotesis, (10) generalisasi dan interpretasi, dan (11) persiapan laporan atau presentasi hasil. 
Instrument yang dikembangkan oleh peneliti berdasarkan aspek-aspek nature of science (NOS) yang terdiri dari Basis Empiris (Empiris Base), Tentatif (Tentative), Teori dan Hukum (Theories and Law), Keterlibatan Sosial Budaya (Socio Cultural embeddednes), Kreativitas (Creativity), Metode Ilmiah (Scientific Method), dan Subjektif (Subjective).
Pada isi instrument terdapat indikator untuk memacu pemahaman nature of science (NOS). Instrument yang dikembankan merupakan hasil ramuan dari pendapat para ahli tentang nature of science (NOS) yang didalamnya terdapat berbagai keterampilan yang harus dikuasai siswa dalam pembelajaran sains yang hasilnya dapat dilihat pada grafik dibawah ini.

\section{Grafik 1.1 Penilaian Responden Terhadap Aspek Nature of Science (NOS)}

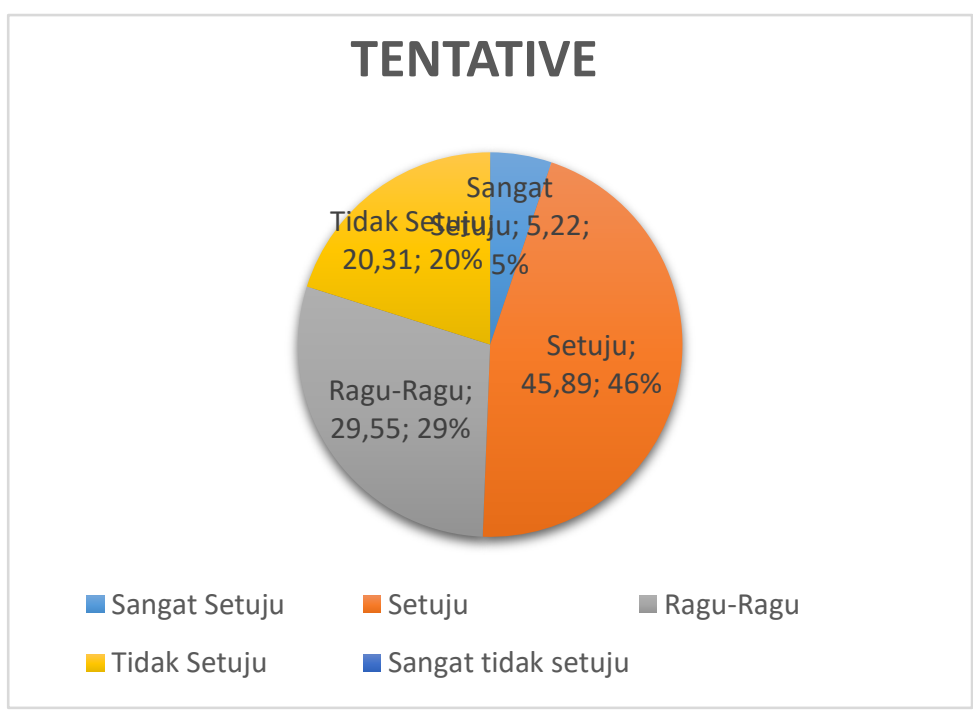

Grafik 1.2 Penilaian Responden Terhadap Aspek Nature of Science (NOS)

\section{EMPIRIS BASE}

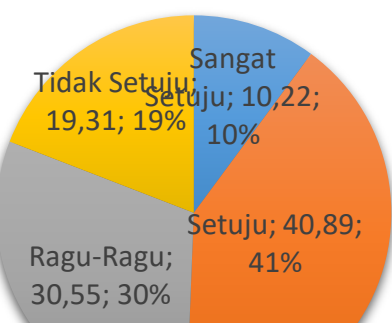


Grafik 1.3 Penilaian Responden Terhadap Aspek Nature of Science (NOS)

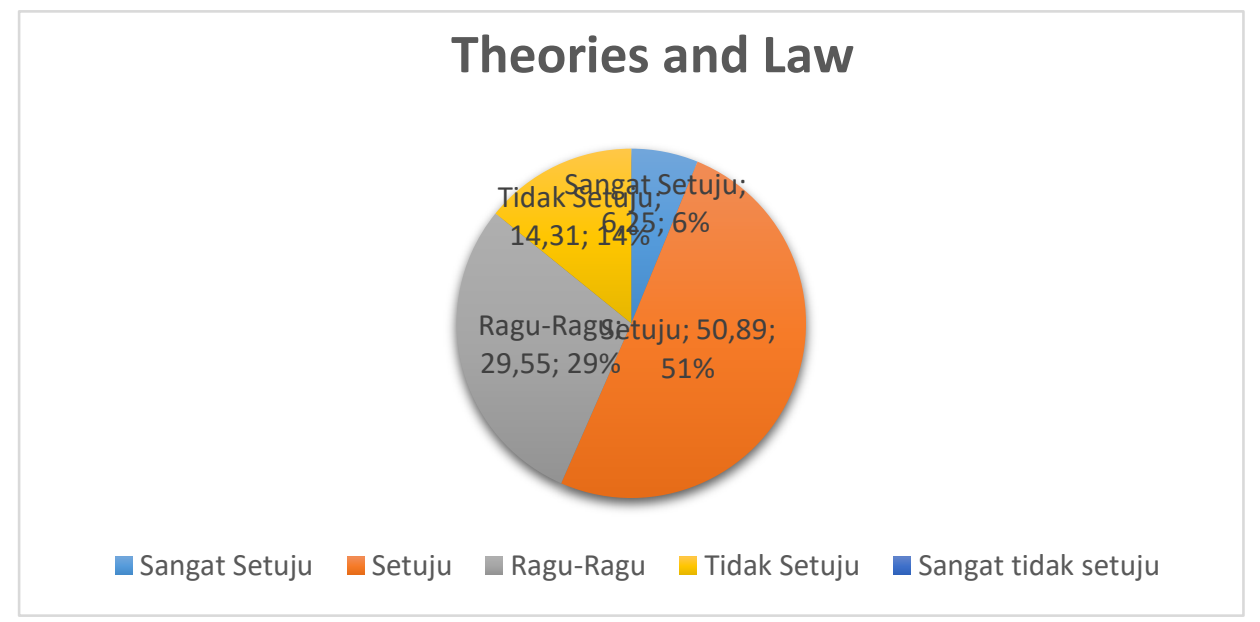

Grafik 1.4 Penilaian Responden Terhadap Aspek Nature of Science (NOS) 
Grafik 1.5 Penilaian Responden Terhadap Aspek Nature of Science (NOS)

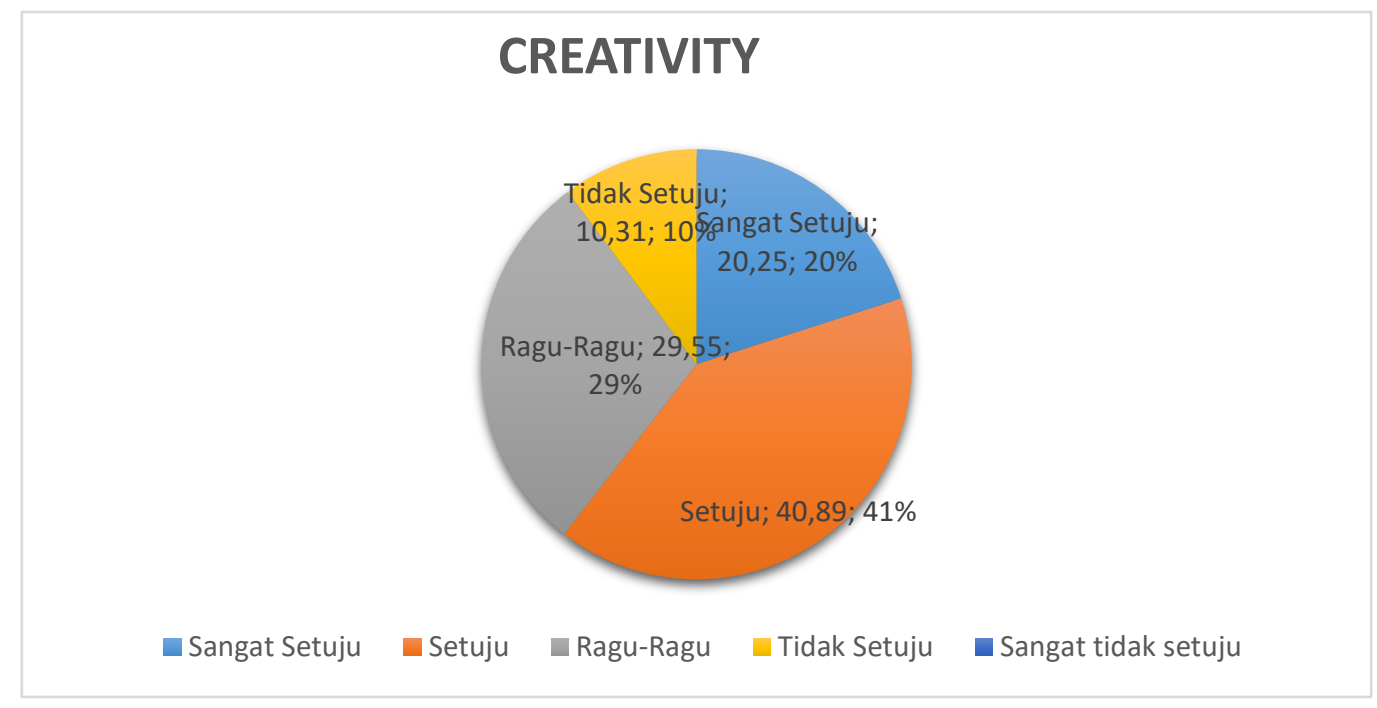

Grafik 1.6 Penilaian Responden Terhadap Aspek Nature of Science (NOS) 


\section{Grafik 1.7 Penilaian Responden Terhadap Aspek Nature of Science (NOS)}

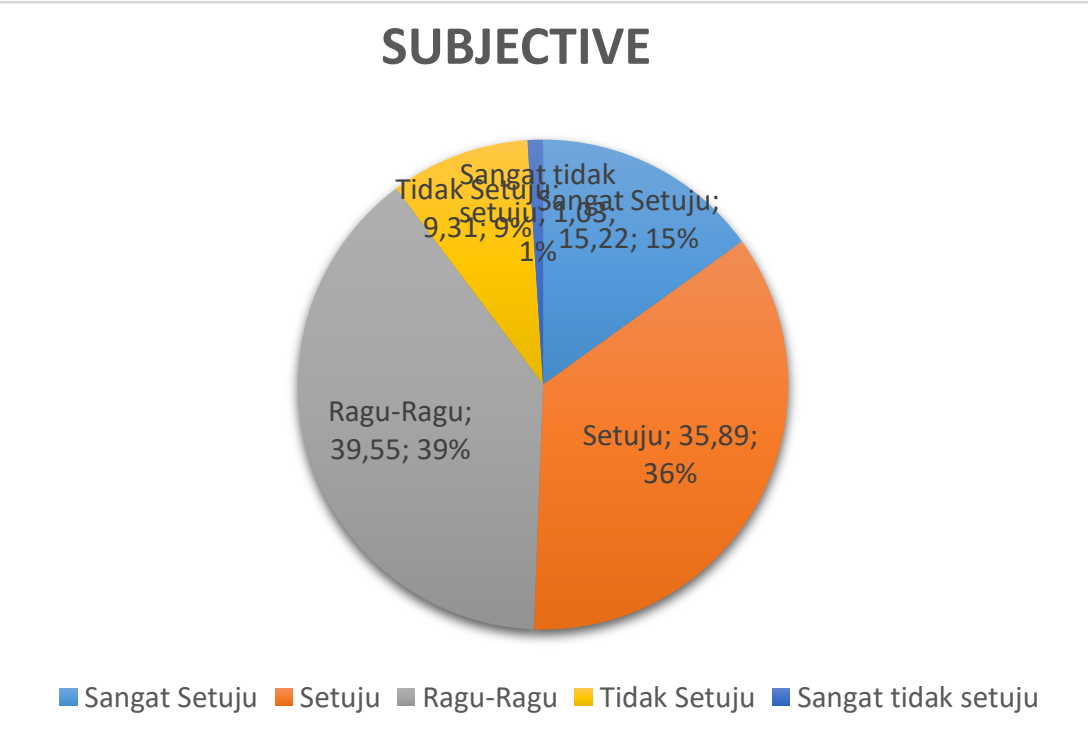


Berdasarkan hasil penilaian dari 45 Responden tentang aspek Nutural of Science (NOS) Tentaive didapatkan dari instrument yang dibagikan yang terdiri: Sangat Setuju 10,22\%, Setuju 26,89\%, RagRagu 22,52\%, dan Tidak Setuju 20,31\%\%,. Hasil penilaian diatas menunjukkan bahwa bahwa aspek tentative secara umum responden pada penelitian ini menilai setuju, tetapi ada beberapa aspek yang perlu ditingkatkan lagi. Ketertarikan dan kemudahan memahami indicator-indokator dari aspek Tentaive tersebut diharapkan mampu menuntun siswa untuk berpartisipasi dalam pembelajaran dan mencapai ketuntasan. Hal tersebut sesuai dengan pendapat Ollington (2008) kegiatan-kegiatan utama di kelas yang menunjukkan siswa berpartisipasi dalam pembelajaran meliputi: menjawab pertanyaan guru, mengerjakan lembar kerja, mencatat, memecahkan masalah, medengarkan penjelasan guru, mengamati demonstrasi guru, mengerjakan soal tes, mengajukan/membuat pertanyaan, dan melakukan eksperimen.

Berdasarkan hasil penilaian dari 45 Responden tentang aspek Nutural of Science (NOS) empiris base didapatkan dari instrument yang dibagikan yang terdiri: Sangat Setuju 10,22\%, Setuju 40,89\%, Ragu-Ragu 29,52\%, dan Tidak Setuju
19,31\%. theories and law didapatkan dari instrument yang dibagikan yang terdiri: Sangat Setuju 6,25\%, Setuju 50,89\%, RagRagu 29,52\%, dan Tidak Setuju 14,31\%. socio cultural embeddednes didapatkan dari instrument yang dibagikan yang terdiri: Sangat Setuju 15,25\%, Setuju 46,89\%, Ragu-Ragu 29,55\%, dan Tidak Setuju 9,31\%. J creativity didapatkan dari instrument yang dibagikan yang terdiri: Sangat Setuju 20,25\%, Setuju 40,89\%, Ragu-Ragu 29,55\%, dan Tidak Setuju 10,31\%. scientific method didapatkan dari instrument yang dibagikan yang terdiri: Sangat Setuju 10,25\%, Setuju 45,89\%, Ragu-Ragu 34,55\%, dan Tidak Setuju 10,31\%. subjective didapatkan dari instrument yang dibagikan yang terdiri Sangat Setuju 15,22\%, Setuju 35,89\%, Ragu-Ragu 39,55\%, dan Tidak Setuju 9,31\%, dan Sangat tidak setuju 1,03\%.

Hasil penilaian diatas menunjukkan bahwa bahwa aspek nature of science (NOS) secara umum responden pada penelitian ini menilai setuju, tetapi ada beberapa aspek yang perlu ditingkatkan. Hal tersebut terjadi karena beberapa indikator memiliki ranah pengetahuan yang tinggi, penemuan dalam pembelajaran siswa memerlukan bimbingan lebih dalam mensintesis atau menggabungkan dua persamaan dan mengevaluasi data soal untuk mengambil 
keputusan. Hal tersebut sesuai dengan pendapat Anderson \& Krattwohl (2001) bahwa proses kognitif yang paling banyak dijumpai dalam tujuan-tujuan di bidang pendidikan, yaitu mengingat, kemudian memahami dan mengaplikasikan, ke proses-proses kognitif yang jarang dijumpai, yakni menganalisis, mensintesis, dan mengevaluasi. Pada aspek-aspek diatas menekankan pada kemampuan sains siswa. Sesuai pendapat Morrison, Ross, Kalman, \& Kemp (2011) untuk mengajarkan faktafakta, maka siswa disajikan pengalaman terhadap fakta

Pengalaman siswa bisa didapatkan dalam kehidupan sehari-hari, atau ketika mengikuti

pembelajaran yang mengisyaratkan siswa lansung kelapangan sehingga siswa bisa melihat, mendengar, dan menyentuh, bahkan apabila situasi mendukung keselamatan siswa bisa merasakan bau dan rasa (Koschmann, 2011). Untuk mendukung kelengkapan data yang dikumpulkan siswa, maka penliti melakukan penilaian pemahaman nature of science pada guru kelas yang mengajar mata pelajaran IPA. Hal ini disebabkan masalah dalam pemahaman siswa tentang NOS tidak terlepas dari pemahaman NOS guru mereka (Lederman 1992). Hasilnya dapat dilihat pada grafik dibawah ini..

\section{Grafik 1.8 Penilaian Responden Terhadap Aspek Nature of Science (NOS)}

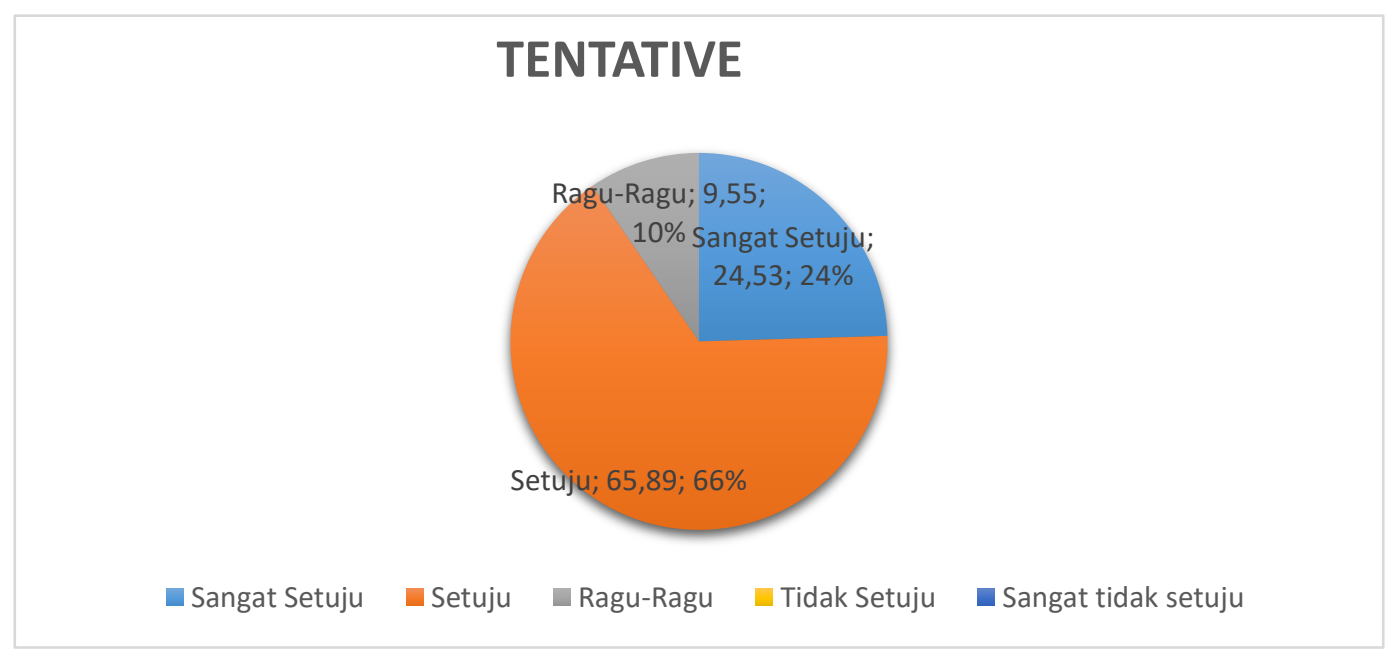

Grafik 1.9 Penilaian Responden Terhadap Aspek Nature of Science (NOS) 


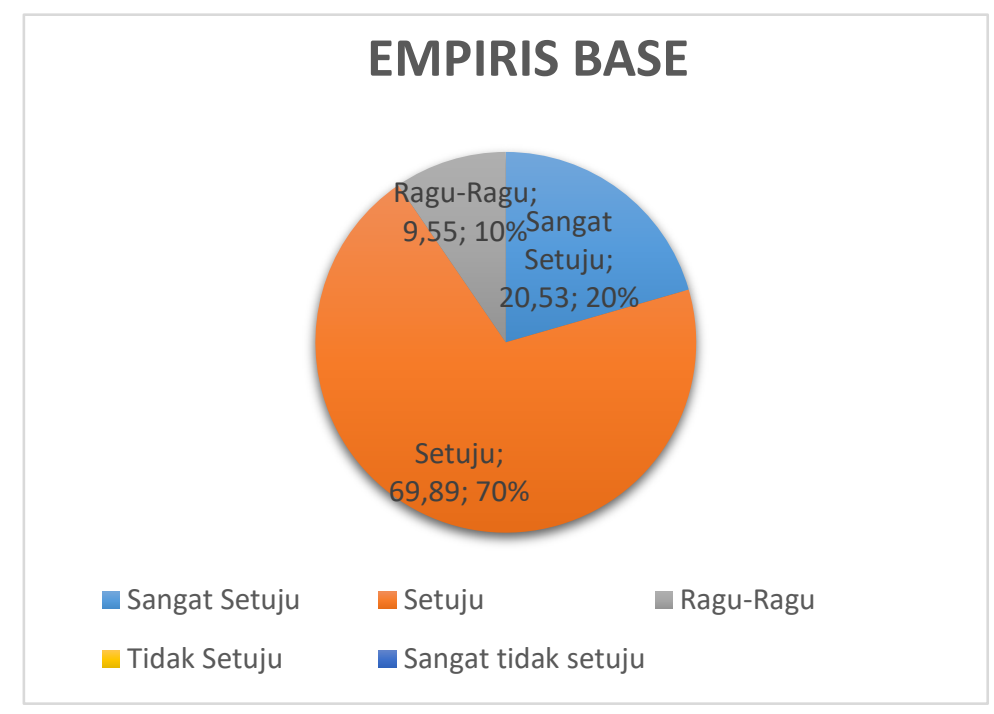

Grafik 1.10 Penilaian Responden Terhadap Aspek Nature of Science (NOS)

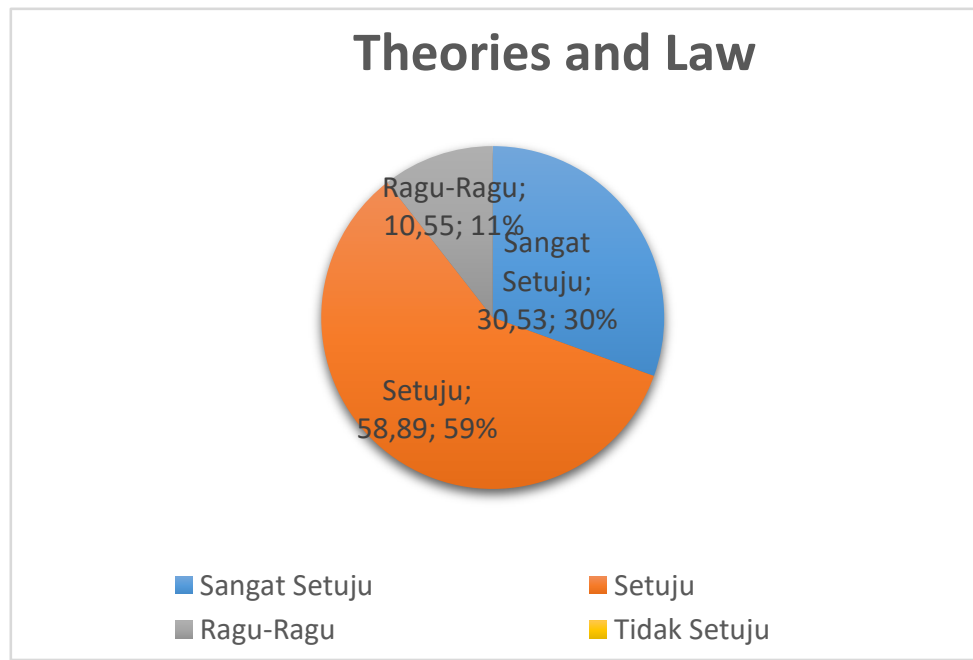

Grafik 1.11 Penilaian Responden Terhadap Aspek Nature of Science (NOS) 


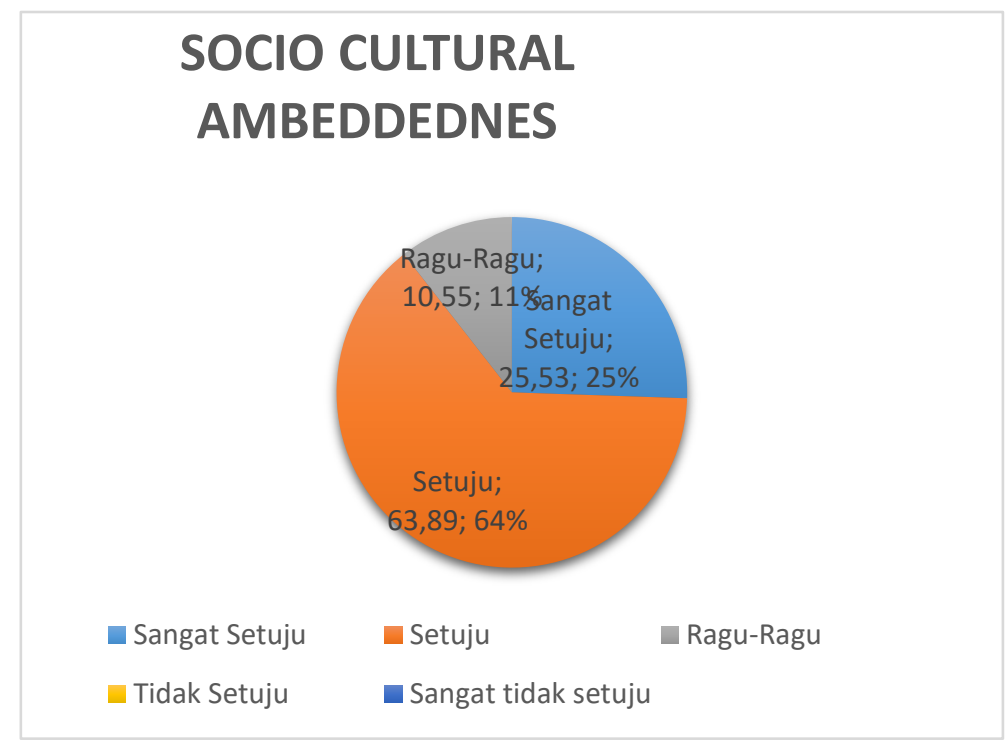

Grafik 1.12 Penilaian Responden Terhadap Aspek Nature of Science (NOS)

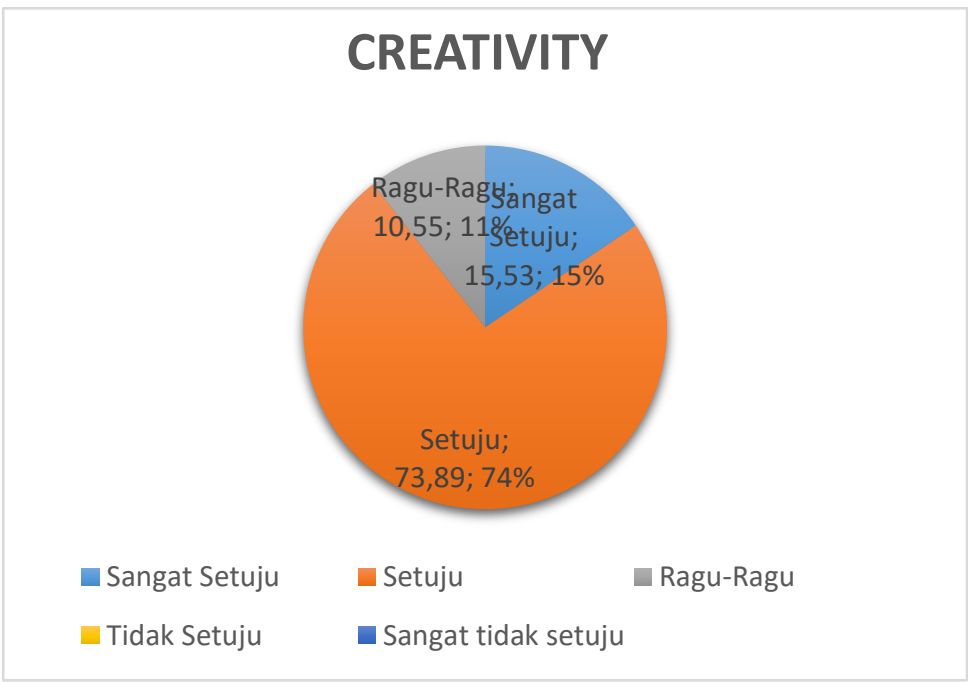

Grafik 1.13 Penilaian Responden Terhadap Aspek Nature of Science (NOS) 


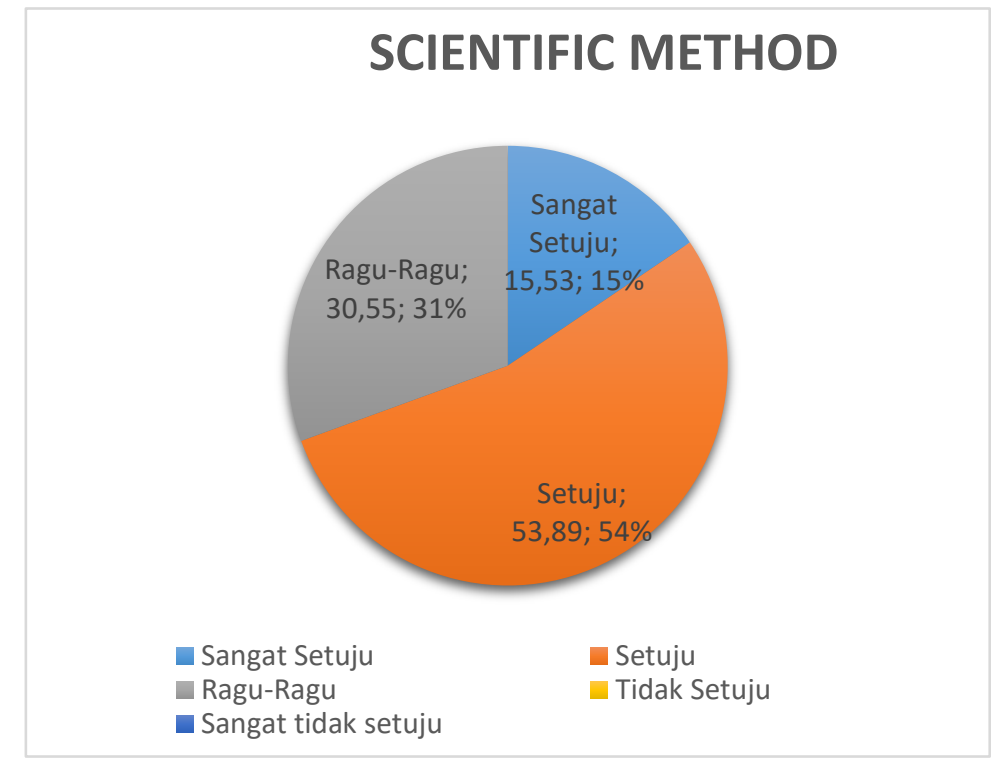

\section{Grafik 1.14 Penilaian Responden Terhadap Aspek Nature of Science (NOS)}

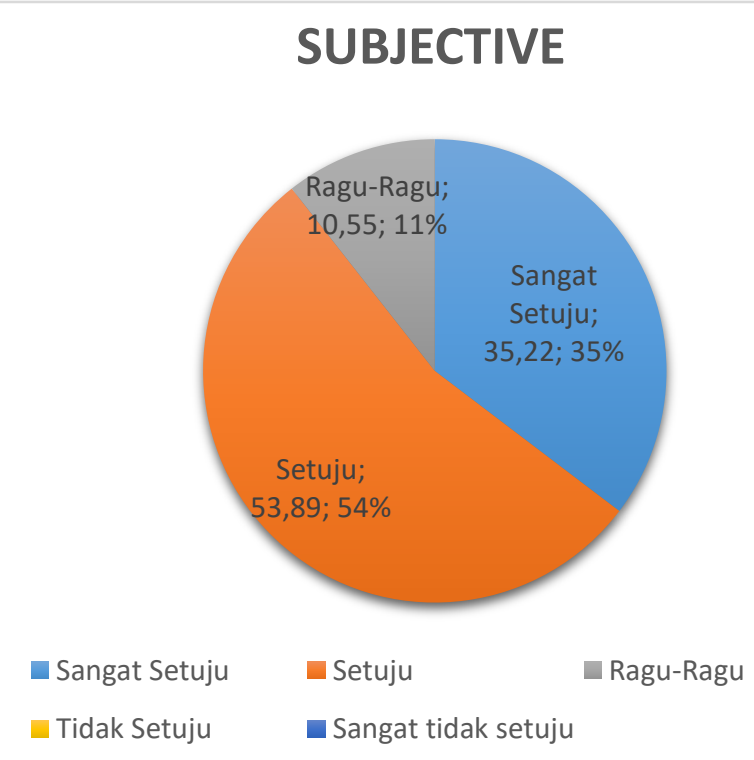

Berdasarkan hasil penilaian dari 2 instrument yang dibagikan yang terdiri: Responden tentang aspek Nutural of terdiri Sangat Setuju 24,53\%, Setuju Science (NOS) Tentaive didapatkan dari 65,89\%, dan Ragu-Ragu 9,55\%,. empiris 
base didapatkan dari instrument yang dibagikan yang terdiri: terdiri Sangat Setuju 20,53\%, Setuju 69,89\%, dan Ragu-Ragu 9,55\%,. theories and law didapatkan dari instrument yang dibagikan yang terdiri: terdiri Sangat Setuju 30,53\%, Setuju 58,89\%, dan Ragu-Ragu 10,55\%, socio cultural embeddednes didapatkan dari instrument yang dibagikan yang terdiri: terdiri Sangat Setuju 25,53\%, Setuju 63,89\%, dan Ragu-Ragu 10,55\%,. creativity didapatkan dari instrument yang dibagikan yang terdiri: terdiri Sangat Setuju 15,53\%, Setuju 73,89\%, dan Ragu-Ragu 10,55\%,. scientific method didapatkan dari instrument yang dibagikan yang terdiri: terdiri Sangat Setuju 15,53\%, Setuju 53,89\%, dan Ragu-Ragu 30,55\%,. subjective didapatkan dari instrument yang dibagikan yang terdiri: terdiri Sangat Setuju 35,53\%, Setuju 53,89\%, dan Ragu-Ragu 10,55\%. Hasil penilaian diatas menunjukkan bahwa bahwa semua aspek secara umum responden pada penelitian ini menilai setuju, tetapi ada beberapa aspek yang perlu ditingkatkan lagi.

Pada penilaian guru tentang nature of science (NOS) mendukung informasi dan kemudahan dalam memahami aspek-aspek NOS. Respon guru terhadap komponen aspek-aspek NOS didapatkan hasil bahwa guru menyatakan setuju dan cukup mudah mempelajari dan memahami keterampilan natural of science. Penialaian positif guru tersebut diharapkan dapat memberikan harapan perubahan penyelesaian masalahmasalah yang nantinya dapat betul-betul diajarkan kepada siswa. Hal tersebut senada dengan pendapat Tawil \& Cougoureux (2013) bahwa paradigma pembelajaran seumur hidup didasarkan pada empat pilar utama yang mendasari pendidikan dan kehidupan, salah satunya adalah belajar untuk melakukan (Learning to do) yang menekankan pada perolehan keterampilan

Definisi sederhana dari pembelajaran meliputi: (1) pembelajran membantu peserta didik untuk memperoleh pengetahuan dan keterampilan baru, (2) pembelajaran utama terdiri dari memberitahu, menunjukkan, membimbing siswa dalam tugas-tugas kinerja dan kemudian mengukur hasil (Singer, Murphy, \& Hines, 2003).

Hal ini sesuai dengan kompetensi lulusan yang merupakan kualifikasi kemampuan lulusan yang mencakup sikap, pengetahuan, dan keterampilan peserta didik yang harus dipenuhinya atau dicapainya dari suatu satuan pendidikan pada jenjang pendidikan dasar dan menengah (Depdikbud, 2013). 


\section{SIMPULAN}

Setiap peserta didik pada dasarnya dikehendaki memiliki pemahaman yang dapat digunakan dalam kehidupan seharihari sebagai hasil dari proses pembelajaran. Penguatan pengetahuan siswa dapat menjawab tantangan persaingan secara global yang dapat membentuk peserta didik yang memiliki cara berpikir kritis, sistematis, bertanggung jawab, kooperatif serta ikut dalam perkembangan pndidikan di Negara ini. Berdasarkan hasil temuan pada 45 siswa dan 2 guru kelas $V$ di sekolah dasar di kabupaten Enrekang Provinsi Sulawesi selatan dan Kabupaten Purwakarta tentang pemahaman aspekaspek Nature of Science (NOS) di sekolah dasar menggambarkan penilaian yang luar biasa.

Berdasarkan hasil analisis
data dapat disimpulkan bahwa secara
umum responden pada penelitian ini setuju
dengan indicator aspek-aspek Nature of
Science (NOS).

\section{DAFTAR PUSTAKA}

Akerson, V. L., Abd-El-Khalick, F., \& Lederman, N. G. (2000). Influence of a reflective explicit activitybased approach on elementary teachers' conceptions of nature of science. Journal of
Research in Science Teaching, 37(4), 295-317..

Aiken, L.R. (1997). Psychological Testing and Assessment. New York: McGraw-Hill.

Allan, F., Angela, C., Vanessa, V.H., Dilek, O. and Fayez, A. (2012). "Inquirybased science education as multiple outcome interdisciplinary research and learning (MOIRL)". Science Education International. Vol.23. No.4. December 2012. 328-337.

Anderson, L. W. \& Krathwohl, D. R. (2001). A Taxonomy for Learning, Teaching, and Assessing: $A$ Revision of Bloom's Taxonomy of Educational objectives. New York: Longman, Inc.

Arends, R.I. (2007). Learning to Teach (Belajar untuk Mengajar) Edisi ketujuh Buku Satu. Yogyakarta: Pustaka Belajar.

Arends, R.I. (2007). Learning to Teach (Belajar untuk Mengajar) Edisi ketujuh Buku Dua. Yogyakarta: Pustaka Belajar.

Borich, G.D. (1994). Observation Skill of Effective Teaching. New York: Macmillan Publishing Company.

Depdiknas. (2008). Panduan Pengembangan Bahan Ajar. http://www.slideshare.net/mmubar aq/panduan-pemgembangan-bahanajar

Grondlound, N.E. (1982). Construction achievment test, third edition. Engelwood Clift : Prentice - Hall.Inc 
Hake, R.R. (1999). American Educational Research Association's Division D. Measurement and Research Methodology: Analazing Change/Gain Score. USA: Woodland Hills.

Joyce, B., Weil, M., and Shower, B. (1992). Models of Teaching. Fourth Edition. New York: Allyn And Bacon Publishing Company.

Kothari, C. (2004). Reasearch methodology, methods and techniques. New Delhi: New Age International (P) Ltd., Publishers.

Lederman, N. G. (1992). Students' and teachers' conceptions about the nature of science: A review of the research. Journal of Research in Science Teaching, 29, 331-359.

Lederman, N. G. (2007). Nature of science: Past, present, and future. In S. K. Abell \& N. G. Lederman (Eds.), Handbook of research on science education (pp. 831-879). Mahwah, NJ: Lawrence Erlbaum Associates.

Lederman, N. G., \& Abd-El-Khalick, F. (1998). Avoiding de-natured science: Activities that promote understanding of the nature of science. In W. McComas (Ed.), The nature of science in science education: Rationales and strategies (pp. 83-126).
Morrison, G. R., Ross, S. M., Kalman, H. K., \& Kemp, J. K. (2011). Designing effective instruction. USA: John wiley \& Sons, INC.

Ollington, G. F. (2008). Teachers and teaching: strategies, innovations, and problem solving. New York: Nova Science Publishers, Inc.

Osborne, J., Collins, S., Ratcliffe, M., Millar, R., \& Duschl, R. (2003). What "ideasabout-science" should be taught in school science? A Delphi study of the expert community. Journal of Research in Science Teaching, 40(7), 692-720.

Singer, A. J., Murphy, M., \& Hines, S. M. (2003). Teaching to learn, learn to teach. London: Lawrence Erlbaum Associates.

Tawil, S., \& Cougoureux, M. (2013, Januari 1). UNESCO education research and foresight. Dipetik April 4, 2014, dari Revisiting learning: the treasure within:

http://unesdoc.unesco.org/images/ $\underline{0022 / 002200 / 220050 \text { e.pdf }}$

Tsai, H.C., Lee, S.S., Wann, S.R., Huang, T.S., Chen, Y.S., dan Liu, Y.C. 2005. Streptococcus suis meningitis with ventriculoperitoneal shunt infection and spondylodiscitis. J Formos Med Assoc. Vol 104: 948-950.. 